\title{
THBS4, a novel stromal molecule of diffuse-type gastric adenocarcinomas, identified by transcriptome-wide expression profiling
}

\author{
Susann Förster ${ }^{1}$, Stephan Gretschel ${ }^{2}$, Thomas Jöns ${ }^{3}$, Masakazu Yashiro ${ }^{4}$ and \\ Wolfgang Kemmner ${ }^{1}$
}

${ }^{1}$ Research Group Surgical Oncology, Experimental and Clinical Research Center (a joint cooperation between the Charité Medical Faculty and the Max Delbrück Center for Molecular Medicine), Berlin, Germany;

${ }^{2}$ Department of General, Visceral, Vascular and Thoracic Surgery, Charité University Hospital Berlin, Berlin, Germany; ${ }^{3}$ Institute of Integrative Neuroanatomy, Center for Anatomy, Charité University Hospital Berlin, Berlin, Germany and ${ }^{4}$ Department of Surgical Oncology, Osaka City University Graduate School of Medicine, Osaka, Japan

\begin{abstract}
Gastric adenocarcinomas can be divided into two major histological types, the diffuse and intestinal type (Laurén classification). Since they diverge in many clinical and molecular characteristics, it is widely accepted that they represent distinct disease entities that may benefit from different therapeutic approaches. Gene expression profiling studies have identified numerous genes that are differentially expressed between them. However, none of these studies covered the whole transcriptome and the published gene lists reveal little overlap, raising the need for further, more comprehensive analyses. Here, we present the first transcriptome-wide expression profiling study comparing the two types (diffuse $n=19$, intestinal $n=24$ ), which identified $>1000$ genes that are differentially expressed. Among them, thrombospondin 4 (THBS4) showed the strongest correlation to histological type, with vast overexpression in the diffuse type. Quantitative real-time PCR validated this strong overexpression and revealed that intestinal tumors generally lack THBS4 expression. Immunohistochemistry demonstrated THBS4 overexpression on the protein level $(n=10)$ and localized THBS4 to the stromal aspect. Its expression was primarily observed within the extracellular matrix surrounding the tumor cells, with the highest intensities found in regions of high tumor cell density and invasion. Intestinal tumors and matched non-neoplastic gastric epithelium and stroma did not feature any relevant THBS4 expression in a preliminary selection of analyzed cases $(n=5)$. Immunohistochemical colocalization and in vitro studies revealed that THBS4 is expressed and secreted by cancer-associated fibroblasts. Furthermore, we show that THBS4 transcription in fibroblasts is stimulated by tumor cells. This study is the first to identify THBS4 as a powerful marker for diffuse-type gastric adenocarcinomas and to provide an initial characterization of its expression in the course of this disease. Modern Pathology (2011) 24, 1390-1403; doi:10.1038/modpathol.2011.99; published online 24 June 2011
\end{abstract}

Keywords: cancer-associated fibroblasts; gastric adenocarcinoma; gene expression profiling; Laurén classification; tumor stroma

Gastric adenocarcinoma is a potentially deadly disease in most countries due to rather late detection at advanced stages. ${ }^{1-3}$ Our understanding of this

Correspondence: Dr S Förster, Research Group Surgical Oncology, Experimental and Clinical Research Center, Lindenberger Weg 80, Berlin 13125, Germany.

E-mail: susann.foerster@mdc-berlin.de

Received 31 August 2010; revised 15 April 2011; accepted 18 April 2011; published online 24 June 2011 cancer entity is still limited and molecular features are only just emerging as tools for use in individualized treatment (eg Trastuzumab/Herceptin ${ }^{\circledR}$ for HER2-positive cases; ToGA study ${ }^{4}$ ). Gastric adenocarcinomas can histologically be divided into two major types, the 'intestinal' and 'diffuse' type (Laurén classification $^{5}$ ). The intestinal type is characterized by cohesive cells that form gland-like structures and that grow tissue expanding. In the diffuse type, tumor cells lose cell-to-cell interactions 
and infiltrate the stroma of the stomach as single cells or small subgroups, leading to a population of non-cohesive, scattered tumor cells. ${ }^{5,6}$ Diffuse-type gastric adenocarcinomas are further divided into specific subtypes: signet ring cell carcinomas, in which intracellular mucus causes the nuclei to be pushed to the side, and scirrhous carcinomas (linitis plastica), which are accompanied by excessive fibrosis (desmoplasia). In general, the proliferation of connective tissue and mucus production is less prominent in intestinal-type tumors. ${ }^{6}$ Although the Laurén classification system dates back to the 1960s, it is still widely accepted and used by pathologists and surgeons today and represents a simple and robust classification approach. Despite the fact that other, more complex classification systems have been established over the years, all of them essentially overlap with the Laurén system. For example, the well and moderately differentiated 'tubular' and 'papillary' types as defined by the WHO and the 'expanding' type according to Ming's classification correspond roughly to the intestinal type. On the other hand, the WHO types 'undifferentiated carcinoma' and 'signet ring cell carcinoma', as well as the 'infiltrative' type of Ming, generally match the diffuse type. ${ }^{7-9}$

The two Laurén types reveal several divergent clinical and molecular characteristics, including their etiology, epidemiology, carcinogenesis and progression, mRNA and/or protein expression profile, gene copy numbers, microsatellite instability, loss of heterozygosity and mutation profile. ${ }^{8}$ Thus, it is widely accepted that they represent distinct disease entities that may benefit from different therapeutic approaches.

High-throughput gene expression profiling has identified multiple genes whose mRNA expression is different in comparison of the two types. ${ }^{10-14}$ However, these studies have produced gene lists with little overlap, which means that further and more comprehensive analyses are necessary to achieve a clear distinction between the two. Moreover, their gene expression profiles have not yet been analyzed on a genome-wide level. This suggests that many differentially expressed genes or even strong marker or classifier genes may not yet have been discovered. In order to provide the missing data and fully characterize the two types, we performed transcriptome-wide gene expression profiling. Furthermore, we biologically interpreted each profile in search of insights into the molecular mechanisms underlying the type's behavior. Special emphasis was placed on the diffuse type, because it is explicitly more invasive and aggressive than the intestinal one, resulting in poorer prognosis for affected patients, ${ }^{15,16}$ and is of increasing incidence worldwide. ${ }^{17,18}$ Novel insights regarding its molecular background and behavior may lead to a more effective, entity-specific treatment.

Non-microdissected tissue samples (whole specimens, $\geq 75 \%$ tumor content) were used for this study to allow a more global description of the tumor scenario, instead of focusing on the tumor cells alone. This approach has been driven by recent advances in cancer research that had revealed a strong relevance of tumor-stroma interactions for cancer progression. ${ }^{19,20}$

\section{Materials and methods}

\section{Patients and Tissue Samples}

Tissue samples from patients that had undergone resection for sporadic gastric adenocarcinoma at Robert Roessle Hospital (1995-2003) were enrolled for this study (after informed consent). Resected tumors were classified and staged by an experienced pathologist according to the WHO classification ${ }^{21,22}$ and the TNM staging system ${ }^{23}$ following general pathological guidelines. For histological diagnosis, at least three blocks of formalin-fixed, paraffinembedded tissue from different tumor regions were cut and evaluated (at least three sections per block). If tumors were larger than $3 \mathrm{~cm}$ in diameter, one block per additional $\mathrm{cm}$ of diameter was assessed in the same manner. Diagnoses were made based on the predominant histological component. We decided to use regionally lymphatic disseminated tumors (pN1-3) to insure comparability and reproducibility between cohorts. Patient data can be obtained from Supplementary Tables S3 and S4. Non-fixed and non-embedded parts of the tumors were snap frozen in liquid nitrogen immediately after resection and pathological survey and stored constantly at $-80^{\circ} \mathrm{C}$. For total RNA extraction, one of these cryosamples per tumor was cut with a cryostat. The first and the last sections of each sample $(5 \mu \mathrm{m})$ were HE-stained and examined by a second, blinded pathologist for tumor content and histological type. The cryosections in between were used for RNA extraction. This second pathological evaluation ensures that histological diagnosis applies not only to the tumor in general, but precisely to the region that the RNA was extracted from. RNAs extracted from regions with equivocal diagnosis or mixed-type histology, as well as with tumor content of lower than $75 \%$, were excluded from further analyses.

\section{Total RNA Extraction, Preparation of Biotinylated cRNA, Microarray Hybridization and Scanning}

Tissues were homogenized using a Mikro-Dismembrator U (B. Braun Biotech International $\mathrm{GmbH}$, Melsungen, Germany; $5 \mathrm{~min}$ at $\sim 1200$ shakes/min). RNA extraction from tissues was performed using TRIzol $^{\circledR}$ reagent (Invitrogen, Carlsbad, USA) and RNeasy Mini Kit-based cleanup and on-column DNase I digest (both Qiagen, Valencia, USA). RNA extraction from cells was performed using the RNeasy Mini or Micro Kit with QiaShredder-based disruption and on-column DNase I digest (everything 
Qiagen). RNA quality was determined with the Agilent Bioanalyzer 2100 (Agilent Technologies, Santa Clara, USA). Only RNAs possessing 'RNA integrity numbers' $\geq 7$ were used. In all, $3 \mu \mathrm{g}$ of total RNA were processed with the One-Cycle Target Labeling Kit according to the manufacturer's recommendations. In all, $20 \mu \mathrm{g}$ of fragmented biotinlabeled cRNA were hybridized to the GeneChip ${ }^{\circledR}$ HG U133 Plus 2.0 followed by staining and scanning with the Affymetrix Scanner 3000 (everything Affymetrix, Santa Clara, USA). Hybridization, staining and scanning were carried out in an authorized Affymetrix core facility.

\section{Bioinformatic Microarray Data Analysis and Statistical Analysis}

All GeneChips ${ }^{\circledR}$ (raw data) were quality controlled using the 'affy' and 'affyPLM' package from the Bioconductor project (http://www.bioconductor.org) in $\mathrm{R}$ language (data not shown). All subsequent microarray data analyses were performed using GeneSpring GX 10.0.2 software (Agilent Technologies), unless stated otherwise. CEL-data files were imported into GeneSpring GX, preprocessed according to the GC-RMA algorithm ${ }^{24}$ and baseline transformed to the median of all samples. After preprocessing, the correlation coefficients of GeneChips $^{\circledR}$ (to each other) were calculated and yielded values of $>0.828$ (arithmetic mean $\approx 0.916$; median $\approx 0.916$ ). Microarray data can be obtained from the Gene Expression Omnibus at http:// www.ncbi.nlm.nih.gov/geo (GSE22377).

Genes whose expression between groups of samples was significantly different were identified by Welch-test. To control for false-positives, multiple testing correction techniques including the 'Benjamini and Hochberg False Discovery Rate (FDR)' ${ }^{25}$ and 'Bonferroni Family Wise Error Rate (FWER)' ${ }^{26}$ were applied. The fold change (FC) of expression between two groups was calculated as the fold difference between group means. Gene annotation information was obtained from NetAff $\mathrm{x}^{\mathrm{TM}}$ Analysis Center at http://www.affymetrix.com (state of 09/2009). For hierarchical clustering, 'Euclidean distance' and 'complete linkage' were used as distance metric and linkage algorithm.

\section{Gene Ontology Analysis}

Gene Ontology (GO) analysis was performed using GOSSIP $^{27}$ - a freely available software package that tests whether a molecular function, biological process or cellular location described in the GO system (http://www.geneontology.org/), the so-called GO terms, is significantly associated with a group of interesting genes when compared with a reference group (MicroDiscovery GmbH, Berlin, Germany).

\section{cDNA Synthesis, Quantitative Real-Time PCR and Statistical Analysis}

cDNA was obtained by oligo(dT) $)_{16}$-primed reverse transcription of $1 \mu \mathrm{g}$ total RNA using SuperScript II (Invitrogen). Negative controls were $\mathrm{H}_{2} \mathrm{O}$ controls $\left(\mathrm{H}_{2} \mathrm{O}\right.$ instead of RNA) and minus-RT controls $\left(\mathrm{H}_{2} \mathrm{O}\right.$ instead of SuperScript II). Quantitative real-time PCRs were performed using the TaqMan ${ }^{\circledR}$ system (Applied Biosystems, Carlsbad, USA). The assays used were Hs00170261_m1 (THBS4), 4326315E $(A C T B)$ and 4326317E (GAPDH). ACTB was chosen as the endogenous control for expression studies in gastric cancer tissues since it showed the lowest variability across samples in the microarray data and had been identified as the most appropriate housekeeper for this tissue type. ${ }^{28} G A P D H$ was used to control expression analyses in cell lines. For expression analyses in fibroblasts from indirect coculture experiments, TaqMan ${ }^{\mathbb{B}}$-PCRs were conducted using the 'RNA UltraSense ${ }^{\mathrm{TM}}$ One-Step Quantitative RT-PCR System' (Invitrogen). Quantitation of expression was performed relative to the endogenous control using the comparative

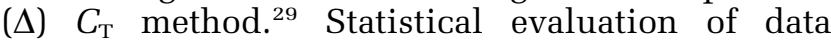
was performed using SPSS 16.0 software (SPSS, Chicago, USA).

\section{Immunohistochemistry and Fluorescence Immunohistochemistry}

Immunohistochemistry was performed on $10 \mu \mathrm{m}$ thin cryosections (mounted on SuperFrost ${ }^{\mathbb{R}}$ Plus microscope slides; Menzel GmbH KG, Braunschweig, Germany) using the biotin blocking system (Dako, Glostrup, Denmark) and the Vectastain Elite ABC Kit (Vector Laboratories, Burlingame, USA) as described previously. ${ }^{30}$ Primary antibody for THBS4 detection was mouse monoclonal anti-human THBS4 (R\&D Systems, Minneapolis, USA; MAB2390; 1:100). Secondary antibody was horse biotinylated anti-mouse IgG $(\mathrm{H}+\mathrm{L})$ (Vector Laboratories; BA-2000; 1:500). Primary antibodies used in fluorescence immunohistochemistry were goat polyclonal anti-human THBS4 (R\&D Systems; AF2390; $1: 200)$, mouse monoclonal anti-pan-cytokeratin [B311.1] (KRT4, 5, 6, 8 10, 13, 18) (GeneTex, Irvine, USA; GTX28474; 1:200), mouse monoclonal anti-VIM [13.2] (Sigma-Aldrich Corporation, St Louis, USA; V 5255; 1:50) and mouse monoclonal anti-human aSMA [1A4] (Dako; M0851; 1:100). Corresponding fluorescently labeled secondary antibodies were donkey Alexa Fluor ${ }^{\circledR} 555$ anti-goat $\operatorname{IgG}(\mathrm{H}+\mathrm{L})$ and donkey Alexa Fluor ${ }^{\circledR} 488$ anti-mouse IgG $(\mathrm{H}+\mathrm{L})$ (Invitrogen; A21432 and A21202, 1:1000).

\section{Cell Culture and Indirect Coculture}

Non-commercially available tumor cell lines OCUM-8 and OCUM-2M, ${ }^{31,32}$ as well as fibroblast 
lines CAF-32/33 and NF-32/33, were obtained from Osaka City University Medical School, Department of Surgical Oncology. The OCUM cell lines had been established from human diffuse/poorly differentiated gastric adenocarcinomas. ${ }^{31,32}$ CAF cell lines had been established from the primary tumor site of diffuse/poorly differentiated gastric adenocarcinomas and NF lines from the 'normal' non-neoplastic counterpart (as matched pairs). The procedure is described elsewhere. ${ }^{33}$ OCUM and fibroblast cell lines were routinely kept in high glucose DMEM (4.5 g/l) with $10 \%$ FBS, $100 \mathrm{U} / \mathrm{ml}$ penicillin, $100 \mu \mathrm{g} / \mathrm{ml}$ streptomycin, $0.5 \mathrm{mM}$ sodium pyruvate and $2 \mathrm{mM}$ L-glutamine at $37^{\circ} \mathrm{C}$ in $5 \% \mathrm{CO}_{2}$ (everything PAA Laboratories, Pasching, Austria). MKN-45 cells $^{34}$ were cultured according to the protocol outlined by the provider (German Collection of Microorganisms and Cell Cultures).

Indirect coculture experiments were conducted using the conditioned medium technique. For preparation of OCUM-conditioned medium, cells were suspended in medium at $6-7 \times 10^{4} \mathrm{cells} / \mathrm{ml}$. After $48 \mathrm{~h}$ of culture, the suspension was centrifuged for $5 \mathrm{~min}(840 \mathrm{~g})$ and the supernatant was collected. To acquire MKN-45-conditioned medium, cells were first cultured until $\sim 80 \%$ confluence. The medium was replaced by fresh medium, followed by $48 \mathrm{~h}$ of culture and centrifugation as described above. All conditioned media were aliquoted and stored at $-80^{\circ} \mathrm{C}$ until use. In all, $2 \times 10^{4}-1 \times 10^{5}$ fibroblasts were seeded in wells of six-well plates (FALCON ${ }^{\circledR}$ flat bottom, Becton Dickinson Labware, Franklin Lakes, USA). After $24 \mathrm{~h}$ of initial culture, the fibroblast medium was replaced by conditioned medium ( $2 \mathrm{ml} /$ well). After $48 \mathrm{~h}$ of culture, fibroblasts were harvested and lysed (RLT buffer; RNeasy Micro Kit, Qiagen). Fresh medium of each tumor cell line was used as control medium. All experiments were performed in triplicate with controls run on the same plate.

\section{Results}

Diffuse and Intestinal-Type Gastric Adenocarcinomas Exhibit Strong Differences in mRNA Expression Profiles

Gastric adenocarcinoma samples that could clearly be assigned to either the intestinal or diffuse type and that contained at least $75 \%$ tumorous tissue were used to form the two histological groups (diffuse $n=19$, intestinal $n=24$ ). Genes differentially expressed between these groups were identified by Welch-test. Significance in differential expression was accepted at multiple testing corrected $P<0.05$ and a meaningful difference in expression at a FC $\geq 2$. Each multiple testing method yielded a different number of genes with significant differences in expression. Applying the Bonferroni FWER, the most conservative and stringent multiple testing technique available, yielded
207 unique annotated transcripts and 44 unique non-annotated ones (322 probe sets). The more moderate technique of Benjamini and Hochberg FDR identified 1280 unique annotated transcripts and 253 unique non-annotated ones (2071 probe sets). In both test systems, the majority of differentially expressed genes (eg $\sim 73 \%$ for FDR) were upregulated in diffuse-type tumors, whereas a smaller number of genes (eg $\sim 27 \%$ for FDR) were upregulated in the intestinal type (Figure 1). Annotated lists of the 50 genes that showed the most significant upregulation in either histological type can be found in Supplementary Tables S1 and S2. Two-way hierarchical clustering using the obtained gene lists resulted in dendrograms comprising two major sample clusters representing the two histological types and two major gene clusters indicating the direction of regulation. However, the use of the gene list gained by FDR resulted in 95.3\% (41 of 43) of the samples being grouped to the respective cluster (Figure 1a), whereas the more stringently selected list of FWER produced a sample dendrogram in which $97.7 \%$ (42 of 43) were grouped 'properly' (Figure 1b). The one misgrouped sample (Figure 1b) was a diffuse-type tumor clustered to the intestinal tumor type. It possessed a very dense tumor cell population with almost no stroma present, a rather uncommon feature of diffuse-type gastric adenocarcinomas.

\section{Genes Upregulated in Diffuse and Intestinal-Type Gastric Adenocarcinomas Belong to Different Biological Processes}

Very stringent multiple testing corrections, such as the Bonferroni FWER, lead to a trade-off in that they may yield high numbers of false-negatives. Hence, the significant genes identified by Benjamini and Hochberg FDR were used for biological interpretation. GO analysis uncovered that genes overexpressed in intestinal-type gastric adenocarcinomas are predominantly associated with proliferation and growth-connected processes, such as the cell cycle and mitosis (Table 1). In contrast, most of the genes upregulated in diffuse-type gastric adenocarcinomas encode for proteins of the extracellular matrix or for proteins that have important roles in adhesion or developmental processes (Table 2). None of the significantly enriched GO terms was shared between the two types.

\section{Thrombospondin 4 - the Most Potent Marker for Diffuse-Type Gastric Adenocarcinoma in This Data Set}

The probe set with the highest FC and lowest $P$-value in this test system represented the thrombospondin 4 (THBS4) transcript. It was 40.8 -fold upregulated in diffuse tumors and held a FDR corrected $P$-value of $1.65 \mathrm{E}-7$. Two-way hierarchical 
a

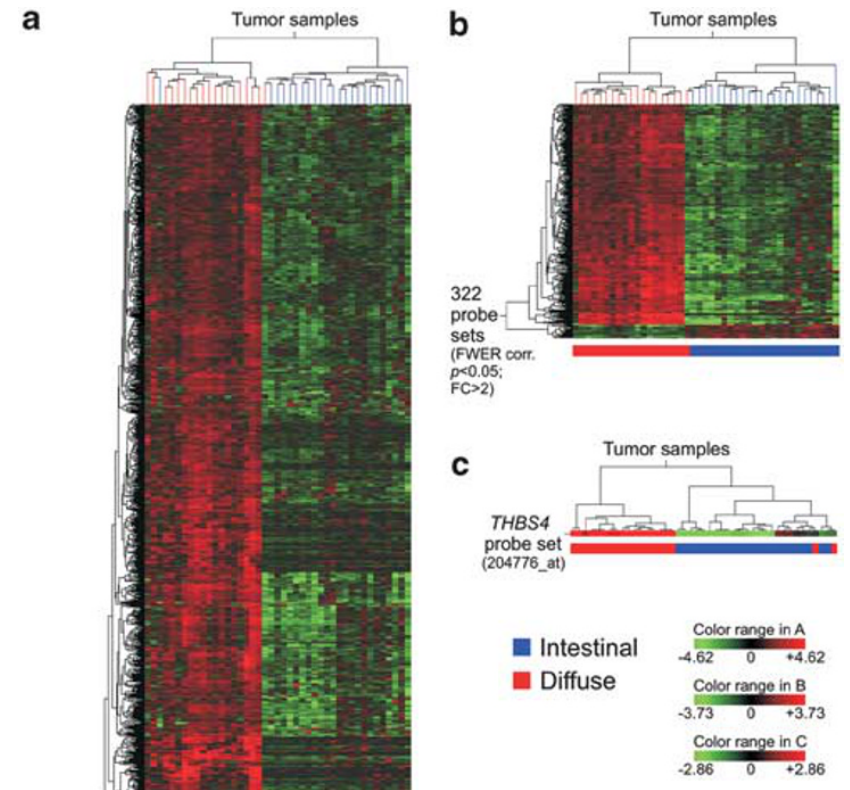

b clustering based on the THBS4 probe set alone yielded the same 'correctness' in sample grouping as when using the whole FDR generated gene signature (Figure 1c). Only two diffuse-type tumors were misgrouped to the intestinal tumor cluster. There were no common unusual histological features to these samples. One was a mucinous adenocarcinoma (G3) with low tumor cell density. The other, in contrast, was an adenocarcinoma (G3) with very dense tumor cells and almost no stroma.

Quantitative real-time PCR was conducted to validate the THBS4 microarray data (on all 43 samples). The analysis clearly confirmed the strong significance in differential mRNA expression $(P<0.0001$, Mann-Whitney $U$-test $)$ and demonstrated that THBS4 mRNA is principally absent from the majority of intestinal-type gastric adenocarcinomas of this cohort, whereas increased amounts are present within the diffuse-type population (Figure 2). A pathological reevaluation revealed that the few intestinal-type tumors that showed some weak expression were all contaminated by small amounts of smooth muscle, mainly because the part of the tumor that had been analyzed was derived from a region where muscle layers had been infiltrated. The PCR analysis additionally showed that the two diffuse gastric adenocarcinoma samples that had been misgrouped to the intestinal population according to clustering (refer to Figure 1c) exhibit slightly higher amounts of THBS4 mRNA than the majority of intestinal samples, but lower amounts than found in the rest of diffuse-type gastric adenocarcinomas. The immunohistochemical detection of THBS4 protein within randomly selected tumor samples confirmed that transcriptional differences are reflected on the protein level. All the diffuse tumors that were examined $(n=10)$ showed specific positivity for THBS4, whereas no notable positivity could be observed in the intestinal-type population $(n=5)$ (Figure 3 ).

\section{Thrombospondin 4 Is a Highly Abundant Tumor Stroma Constituent of Diffuse-Type Gastric Adenocarcinomas} differentially expressed between human diffuse and intestinaltype gastric adenocarcinomas. Genes whose expression was significantly different between diffuse and intestinal-type samples were identified by Welch-test. Different multiple testing techniques were applied to correct for false-positives and resulted in different numbers of significant probe sets passing the test (corrected $P<0.05$; fold change $\geq 2$ ). Different lists were subsequently used for two-way hierarchical clustering. Normalized expression intensities of probe sets are depicted as a heatmap. 'Euclidean distance' and 'complete linkage' were used as distance metric and linkage algorithm for all clusterings. (a) Hierarchical clustering heatmap obtained for the signature of 1533 genes (2071 probe sets) identified by application of Benjamini and Hochberg False Discovery Rate (FDR). (b) Hierarchical clustering heatmap obtained for the signature of 251 genes (322 probe sets) identified by application of Bonferroni Family Wise Error Rate (FWER). (c) Hierarchical clustering heatmap obtained when using the probe set for THBS4, the gene with the strongest significance in this test system, alone.
The localization of THBS4 within diffuse-type gastric adenocarcinomas was traced to the tumor stroma. All the specimens investigated were positive for THBS4 in extracellular fibrillar structures surrounding the tumor cells (Figure 3a and b). In some cases, additional intracellular positivity could be detected in the stroma (Figure 3c and d). Cells showing this cytosolic THBS4 expression were rather small in size and had a fusiform or spindlelike shape, sometimes accompanied by extended cell processes. All of these features hint at a potential fibroblast phenotype. THBS4 expression was particularly strong within regions of high tumor cell density, so-called tumor cell nests (Figure 3c), and at sites of infiltration into adjacent 'healthy' 
Table 1 Significantly enriched Gene Ontology (GO) terms identified for genes overexpressed in human intestinal-type gastric adenocarcinomas

\begin{tabular}{|c|c|c|c|c|c|}
\hline GO identifier & GO term description & $\mathrm{P}$-value & $\begin{array}{l}\text { FDR corr. } \\
\text { P-value }\end{array}$ & $\begin{array}{c}\text { \# in test } \\
\text { list }\end{array}$ & $\begin{array}{c}\text { \# in ref. } \\
\quad \text { list }\end{array}$ \\
\hline GO:0022403 & Cell-cycle phase & $1.72 \mathrm{E}-60$ & $5.57 \mathrm{E}-58$ & 88 & 565 \\
\hline GO:0022402 & Cell-cycle process & $4.38 \mathrm{E}-60$ & $6.56 \mathrm{E}-58$ & 95 & 711 \\
\hline GO:0000279 & M phase & $1.00 \mathrm{E}-59$ & $1.11 \mathrm{E}-57$ & 79 & 419 \\
\hline GO:0000278 & Mitotic cell cycle & $3.08 \mathrm{E}-55$ & $2.58 \mathrm{E}-53$ & 81 & 525 \\
\hline GO:0007049 & Cell cycle & $4.94 \mathrm{E}-53$ & $3.51 \mathrm{E}-51$ & 103 & 1067 \\
\hline GO:0000087 & M phase of mitotic cell cycle & $8.80 \mathrm{E}-53$ & $4.88 \mathrm{E}-51$ & 66 & 309 \\
\hline GO:0005694 & Chromosome & $6.04 \mathrm{E}-36$ & $3.38 \mathrm{E}-34$ & 73 & 789 \\
\hline GO:0044427 & Chromosomal part & $2.61 \mathrm{E}-34$ & $1.30 \mathrm{E}-32$ & 69 & 735 \\
\hline GO:0051726 & Regulation of cell cycle & $5.81 \mathrm{E}-27$ & $2.81 \mathrm{E}-25$ & 52 & 523 \\
\hline GO:0000075 & Cell-cycle checkpoint & $2.22 \mathrm{E}-26$ & $9.35 \mathrm{E}-25$ & 27 & 81 \\
\hline GO:0005819 & Spindle & $1.24 \mathrm{E}-24$ & $5.09 \mathrm{E}-23$ & 23 & 54 \\
\hline GO:0007067 & Mitosis & $5.83 \mathrm{E}-23$ & $2.14 \mathrm{E}-21$ & 27 & 115 \\
\hline GO:0043228 & Non-membrane-bound organelle & $6.44 \mathrm{E}-23$ & $2.14 \mathrm{E}-21$ & 124 & 3458 \\
\hline GO:0043232 & Intracellular non-membrane-bound organelle & $6.44 \mathrm{E}-23$ & $2.14 \mathrm{E}-21$ & 124 & 3458 \\
\hline GO:0044446 & Intracellular organelle part & $2.79 \mathrm{E}-22$ & $8.44 \mathrm{E}-21$ & 150 & 4827 \\
\hline GO:0044422 & Organelle part & $4.16 \mathrm{E}-22$ & $1.18 \mathrm{E}-20$ & 150 & 4847 \\
\hline GO:0007059 & Chromosome segregation & $2.75 \mathrm{E}-21$ & $7.55 \mathrm{E}-20$ & 20 & 49 \\
\hline GO:0000819 & Sister chromatid segregation & $4.62 \mathrm{E}-21$ & $1.22 \mathrm{E}-19$ & 18 & 33 \\
\hline GO:0015630 & Microtubule cytoskeleton & $7.21 \mathrm{E}-21$ & $1.81 \mathrm{E}-19$ & 49 & 641 \\
\hline GO:0007346 & Regulation of mitotic cell cycle & $2.87 \mathrm{E}-20$ & $6.88 \mathrm{E}-19$ & 23 & 92 \\
\hline GO:0006323 & DNA packaging & $4.94 \mathrm{E}-20$ & $1.14 \mathrm{E}-18$ & 35 & 310 \\
\hline GO:0006259 & DNA metabolic process & $2.44 \mathrm{E}-19$ & $5.07 \mathrm{E}-18$ & 56 & 923 \\
\hline GO:0051276 & Chromosome organization and biogenesis & $6.70 \mathrm{E}-19$ & $1.43 \mathrm{E}-17$ & 52 & 814 \\
\hline GO:0006996 & Organelle organization and biogenesis & $3.61 \mathrm{E}-16$ & $7.57 \mathrm{E}-15$ & 86 & 2335 \\
\hline GO:0051325 & Interphase & $8.20 \mathrm{E}-16$ & $1.63 \mathrm{E}-14$ & 24 & 175 \\
\hline GO:0031570 & DNA integrity checkpoint & $1.08 \mathrm{E}-15$ & $2.15 \mathrm{E}-14$ & 17 & 64 \\
\hline GO:0000785 & Chromatin & $7.22 \mathrm{E}-15$ & $1.37 \mathrm{E}-13$ & 29 & 309 \\
\hline GO:0044430 & Cytoskeletal part & $1.07 \mathrm{E}-14$ & $1.94 \mathrm{E}-13$ & 53 & 1079 \\
\hline GO:0051329 & Interphase of mitotic cell cycle & $4.34 \mathrm{E}-14$ & $7.94 \mathrm{E}-13$ & 22 & 171 \\
\hline GO:0005874 & Microtubule & $4.61 \mathrm{E}-14$ & $8.06 \mathrm{E}-13$ & 14 & 44 \\
\hline GO:0031497 & Chromatin assembly & $4.56 \mathrm{E}-13$ & $7.82 \mathrm{E}-12$ & 26 & 289 \\
\hline GO:0007017 & Microtubule-based process & $1.04 \mathrm{E}-12$ & $1.81 \mathrm{E}-11$ & 29 & 382 \\
\hline GO:0006333 & Chromatin assembly or disassembly & $1.52 \mathrm{E}-12$ & $2.54 \mathrm{E}-11$ & 26 & 306 \\
\hline GO:0000226 & Microtubule cytoskeleton organization and biogenesis & $4.67 \mathrm{E}-12$ & $7.45 \mathrm{E}-11$ & 19 & 154 \\
\hline GO:0051327 & M phase of meiotic cell cycle & $5.38 \mathrm{E}-12$ & $8.29 \mathrm{E}-11$ & 17 & 116 \\
\hline GO:0007093 & Mitotic cell-cycle checkpoint & $5.46 \mathrm{E}-12$ & $8.29 \mathrm{E}-11$ & 12 & 40 \\
\hline GO:0051321 & Meiotic cell cycle & $6.08 \mathrm{E}-12$ & $8.80 \mathrm{E}-11$ & 17 & 117 \\
\hline GO:0051301 & Cell division & $6.80 \mathrm{E}-12$ & $9.37 \mathrm{E}-11$ & 15 & 83 \\
\hline GO:0005856 & Cytoskeleton & $3.91 \mathrm{E}-11$ & $5.50 \mathrm{E}-10$ & 57 & 1520 \\
\hline GO:0043231 & Intracellular membrane-bound organelle & $8.84 \mathrm{E}-11$ & $1.26 \mathrm{E}-09$ & 244 & 12726 \\
\hline
\end{tabular}

GO analysis was performed using GOSSIP. ${ }^{27}$ The reference list (ref.) encompassed all genes represented on the array. The 40 GO terms with the strongest significance are depicted sorted by $P$-value (non-corrected and corrected for multiple testing; FDR, False Discovery Rate).

tissues (Figure 3b). Neither the epithelium nor stroma of matched non-neoplastic counterparts $(n=5)$ exhibited any detectable THBS4 expression (Figure 3). The only aspects of the non-neoplastic gastric wall, which definitely showed THBS4 expression, were the smooth muscle layers (interstitial cells and perimysium) of muscularis mucosae and muscularis propria as well as vessel walls (Supplementary Figure S1).

\section{In Diffuse-Type Gastric Adenocarcinomas, Thrombospondin 4 Is Expressed and Secreted by Cancer-Associated Fibroblasts}

Immunohistochemical colocalization studies using markers for various cell entities were conducted to identify the cells featuring cytosolic THBS4 posi- tivity, namely those that express and secrete the protein. Cytokeratins served as markers for cells of epithelial origin (in this case the carcinoma cells). Vimentin was employed to identify fibroblasts and mesenchymal cells in general. $\alpha$-Smooth muscle actin was used to mark myofibroblasts, ${ }^{35}$ which represent a subpopulation of cancer-associated fibroblasts in malignant transformation. None of the THBS4-positive cells showed any positivity for cytokeratins, whereas they all were positive for vimentin and $\alpha$-smooth muscle actin (Figure 4). Thus, cancer-associated fibroblasts of the myofibroblast phenotype are the THBS4-expressing cells in diffuse-type gastric adenocarcinomas.

Additionally, in vitro cell line systems of diffusetype gastric adenocarcinoma-derived cancerassociated fibroblasts and healthy counterpart-derived normal fibroblasts were examined for THBS4 mRNA 
Table 2 Significantly enriched Gene Ontology (GO) terms identified for genes overexpressed in human diffuse-type gastric adenocarcinomas

\begin{tabular}{|c|c|c|c|c|c|}
\hline GO ID & GO term description & $\mathrm{P}$-value & $\begin{array}{c}\text { FDR corr. } \\
\text { P-value }\end{array}$ & $\begin{array}{c}\text { \# in test } \\
\text { list }\end{array}$ & $\begin{array}{c}\text { \# in ref } \\
\text { list }\end{array}$ \\
\hline GO:0031012 & Extracellular matrix & $8.43 \mathrm{E}-63$ & $3.51 \mathrm{E}-60$ & 137 & 484 \\
\hline GO:0005576 & Extracellular region & $5.99 \mathrm{E}-54$ & $8.95 \mathrm{E}-52$ & 189 & 1158 \\
\hline GO:0044421 & Extracellular region part & $5.99 \mathrm{E}-54$ & $8.95 \mathrm{E}-52$ & 189 & 1158 \\
\hline GO:0048856 & Anatomical structure development & $3.40 \mathrm{E}-45$ & $4.27 \mathrm{E}-43$ & 347 & 3798 \\
\hline GO:0032501 & Multicellular organismal process & $4.38 \mathrm{E}-44$ & $4.58 \mathrm{E}-42$ & 475 & 6245 \\
\hline GO:0007275 & Multicellular organismal development & $1.88 \mathrm{E}-42$ & $1.69 \mathrm{E}-40$ & 328 & 3584 \\
\hline GO:0032502 & Developmental process & $4.19 \mathrm{E}-39$ & $3.22 \mathrm{E}-37$ & 438 & 5787 \\
\hline GO:0022610 & Biological adhesion & $7.64 \mathrm{E}-38$ & $5.14 \mathrm{E}-36$ & 188 & 1529 \\
\hline GO:0048731 & System development & $4.72 \mathrm{E}-37$ & $2.84 \mathrm{E}-35$ & 300 & 3333 \\
\hline GO:0005578 & Proteinaceous extracellular matrix & $1.55 \mathrm{E}-34$ & $8.48 \mathrm{E}-33$ & 62 & 164 \\
\hline GO:0044420 & Extracellular matrix part & $2.71 \mathrm{E}-34$ & $1.42 \mathrm{E}-32$ & 62 & 166 \\
\hline GO:0009653 & Anatomical structure morphogenesis & $8.98 \mathrm{E}-31$ & $4.24 \mathrm{E}-29$ & 189 & 1768 \\
\hline GO:0048513 & Organ development & $2.87 \mathrm{E}-28$ & $1.42 \mathrm{E}-26$ & 229 & 2511 \\
\hline GO:0007155 & Cell adhesion & $1.86 \mathrm{E}-21$ & $9.20 \mathrm{E}-20$ & 100 & 776 \\
\hline GO:0005515 & Protein binding & $5.64 \mathrm{E}-19$ & $2.59 \mathrm{E}-17$ & 349 & 5332 \\
\hline GO:0003012 & Muscle system process & $6.78 \mathrm{E}-18$ & $3.03 \mathrm{E}-16$ & 53 & 281 \\
\hline GO:0005581 & Collagen & $1.15 \mathrm{E}-16$ & $5.00 \mathrm{E}-15$ & 24 & 46 \\
\hline GO:0030247 & Polysaccharide binding & $2.71 \mathrm{E}-16$ & $1.09 \mathrm{E}-14$ & 39 & 165 \\
\hline GO:0043062 & Extracellular structure organization and biogenesis & $3.90 \mathrm{E}-16$ & $1.51 \mathrm{E}-14$ & 42 & 196 \\
\hline GO:0001568 & Blood vessel development & $6.44 \mathrm{E}-16$ & $2.29 \mathrm{E}-14$ & 54 & 329 \\
\hline GO:0007399 & Nervous system development & $1.79 \mathrm{E}-15$ & $6.59 \mathrm{E}-14$ & 104 & 1031 \\
\hline GO:0001871 & Pattern binding & $5.15 \mathrm{E}-15$ & $1.83 \mathrm{E}-13$ & 39 & 183 \\
\hline GO:0030198 & Extracellular matrix organization and biogenesis & $7.25 \mathrm{E}-15$ & $2.43 \mathrm{E}-13$ & 20 & 34 \\
\hline GO:0001944 & Vasculature development & $1.10 \mathrm{E}-14$ & $3.53 \mathrm{E}-13$ & 57 & 392 \\
\hline GO:0022008 & Neurogenesis & $3.19 \mathrm{E}-14$ & $1.00 \mathrm{E}-12$ & 73 & 617 \\
\hline GO:0030246 & Carbohydrate binding & $1.14 \mathrm{E}-13$ & $3.45 \mathrm{E}-12$ & 59 & 443 \\
\hline GO:0000902 & Cell morphogenesis & $1.25 \mathrm{E}-13$ & $3.72 \mathrm{E}-12$ & 73 & 636 \\
\hline GO:0032989 & Cellular structure morphogenesis & $2.62 \mathrm{E}-13$ & $7.43 \mathrm{E}-12$ & 74 & 661 \\
\hline GO:0048699 & Generation of neurons & $2.93 \mathrm{E}-13$ & $8.11 \mathrm{E}-12$ & 68 & 577 \\
\hline GO:0030029 & Actin filament-based process & $4.65 \mathrm{E}-13$ & $1.23 \mathrm{E}-11$ & 60 & 473 \\
\hline GO:0009887 & Organ morphogenesis & $1.15 \mathrm{E}-12$ & $2.97 \mathrm{E}-11$ & 72 & 654 \\
\hline GO:0008092 & Cytoskeletal protein binding & $3.29 \mathrm{E}-12$ & $8.16 \mathrm{E}-11$ & 77 & 745 \\
\hline GO:0016477 & Cell migration & $3.78 \mathrm{E}-12$ & $9.69 \mathrm{E}-11$ & 59 & 486 \\
\hline GO:0035295 & Tube development & $5.58 \mathrm{E}-12$ & $1.34 \mathrm{E}-10$ & 47 & 332 \\
\hline GO:0031589 & Cell-substrate adhesion & $6.97 \mathrm{E}-12$ & $1.61 \mathrm{E}-10$ & 38 & 226 \\
\hline GO:0005539 & Glycosaminoglycan binding & $9.89 \mathrm{E}-12$ & $2.28 \mathrm{E}-10$ & 31 & 153 \\
\hline GO:0035239 & Tube morphogenesis & $1.11 \mathrm{E}-11$ & $2.43 \mathrm{E}-10$ & 38 & 230 \\
\hline GO:0022604 & Regulation of cell morphogenesis & $2.07 \mathrm{E}-11$ & $4.38 \mathrm{E}-10$ & 24 & 91 \\
\hline GO:0007154 & Cell communication & $2.32 \mathrm{E}-11$ & $4.93 \mathrm{E}-10$ & 392 & 6990 \\
\hline GO:0030182 & Neuron differentiation & $3.35 \mathrm{E}-11$ & $7.04 \mathrm{E}-10$ & 53 & 432 \\
\hline
\end{tabular}

GO analysis was performed using GOSSIP. ${ }^{27}$ The reference list (ref.) encompassed all genes represented on the array. The 40 GO terms with the strongest significance are depicted sorted by $P$-value (non-corrected and corrected for multiple testing; FDR, False Discovery Rate).

expression. In the two cell line pairs that were examined, cancer-associated fibroblasts contained significantly higher expression levels $(P<0.01, t$-test $)$ than normal fibroblasts with overexpression of $\approx 2$ and $\approx 3.3$ fold, respectively (Figure 5 ).

In order to obtain a more global view of THBS4expressing cells, a panel of human cell lines from different entities was examined for THBS4 mRNA expression. This analysis confirmed that carcinoma cells, regardless of derivation, do not generally express THBS4. A very restricted expression pattern was found in cell lines from other malignancies. Only SH-SY5Y, Daudi and HL-60 exhibited measurable expression levels. The highest expression by far was discovered in HEK-293, a cell line derived from normal embryonic kidney. No relevant expression was found in the only fibroblast cell line in this study, derived from normal forehead skin and designated 142BR (Supplementary Figure S2).

\section{Overexpression of Thrombospondin 4 in Gastric Fibroblasts Is Stimulated by Tumor Cells}

To evaluate whether THBS4 expression in fibroblasts is triggered by tumor cells, an in vitro indirect coculture model was established. Two pairs of matching normal and cancer-associated fibroblasts were analyzed for changes in THBS4 mRNA expression when challenged with different tumor cellconditioned media. The treatment with conditioned medium from OCUM-2M and OCUM-8, two cell lines derived from scirrhous gastric carcinomas (a subpopulation of diffuse-type gastric adenocarcinomas marked by excessive fibrosis), resulted in significantly elevated expression levels in both normal fibroblast lines $(P<0.05, t$-test $)$. In cancerassociated fibroblasts, only OCUM-8-conditioned medium yielded significant increases $(P<0.05$, $t$-test). OCUM-2M-conditioned medium showed 


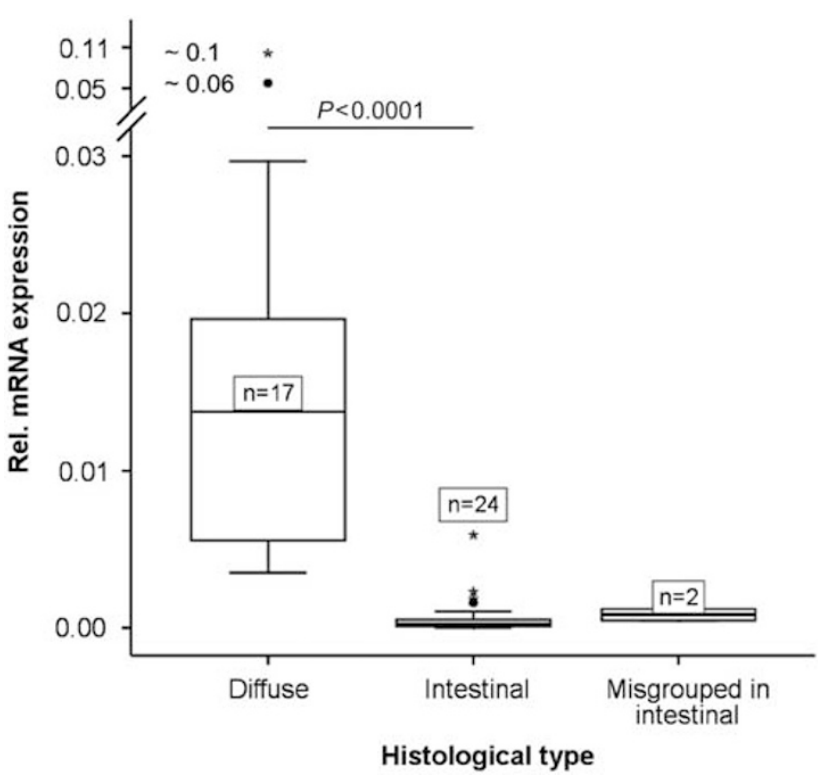

Figure 2 THBS4 mRNA expression in human diffuse and intestinal-type gastric adenocarcinomas. The mRNA abundance of THBS4 was examined by means of quantitative real-time PCR. Quantitation was done relative to the transcript of actin, $\beta$ $(A C T B)$. Significance in differential expression between groups was calculated using Mann-Whitney $U$-test. Expression value distribution within groups is displayed by box and whisker plots.

tendencies for significance, though $(P<0.1, t$-test $)$. The conditioned medium from the non-scirrhous, diffuse-type gastric adenocarcinoma-derived cell line MKN-45 was not able to significantly alter THBS4 expression in all fibroblasts (Figure 6).

\section{Discussion}

According to this transcriptome-wide data set, mRNAs of $>1000$ genes are differentially expressed between diffuse and intestinal-type gastric adenocarcinomas. The pattern of differential expression is so strong that it allows a separation of tumors into these two histological groups according to clustering algorithms. Thus, in concordance with other studies, this work demonstrates that a gene expression profile-based stratification of these histological types of gastric adenocarcinoma is possible and useful, and that phenotypic differences are reflections of broad molecular distinctiveness. ${ }^{10-13,36}$ However, this study is the first to analyze gene expression on a transcriptome-wide level, thus, providing the most comprehensive view of gene expression profiles possible to date. This also explains why the study revealed a higher number of differentially expressed genes than had been found in previous work.

Genes expressed at markedly different strength in the two gastric adenocarcinoma types are connected to different biological processes. Genes in the intestinal type were strongly linked to proliferation and growth-connected processes, whereas diffusetype carcinomas were rather marked by processes related to the extracellular matrix and adhesion. These findings are fully consistent with previous studies. ${ }^{10,11}$ However, this work is the first to use a statistical approach to underline the strong differences in biology and gene functions between these two types of adenocarcinomas.

In this data set, thrombospondin 4 (THBS4) was the most potent marker for diffuse-type gastric adenocarcinoma with vast transcriptional and protein overexpression. Its expression was principally absent in intestinal-type gastric adenocarcinomas. The faint levels seen in a few intestinal gastric adenocarcinomas during PCR analysis (Figure 2) can most likely be attributed to the small amounts of smooth muscle contamination present in these samples. Smooth muscle was the only aspect of non-neoplastic gastric tissue, which displayed THBS4 expression (Supplementary Figure S1).

THBS4 is a secreted multidomain glycoprotein of the extracellular matrix belonging to a family of at least five thrombospondins. ${ }^{37}$ The only literature record on THBS4 in the scenario of gastric cancer is a meta-analysis of three independent sets of microarray data from gene expression studies, which had assigned a putative overexpression of it to the diffuse type ${ }^{36}$ However, the study did not carry out a validation or examination on the protein level (Table 3). This study did also not examine which cells express THBS4. THBS4 does not appear in any of the published gene lists from other gene expression profiling studies aimed at identifying molecules that were differentially expressed or establishing robust classifiers..$^{11,13,38}$ Reasons for this may include that it was either not among the genes with the highest significance or that the customized microarrays that were used did not contain probes for it. Unfortunately, this cannot be determined from the data.

We identified THBS4 as a heavily accumulated constituent of the tumor stroma of diffuse-type gastric adenocarcinomas that is basically absent from intestinal-type tumors. Since healthy counterparts were also negative, THBS4 expression seems to be a diffuse-type gastric adenocarcinoma-specific event and not a remnant of healthy gastric epithelium or stroma. THBS4 expression was seen as an event taking place in the immediate vicinity of tumor cells with the highest intensities found in regions of high tumor cell density. Thus, it is likely that THBS4 expression is somehow regulated by the tumor cells, and also that the protein has potential functions in their behavior in return. Since especially high expression was observed in regions of invasion, THBS4 may have a role in the invasion and metastasization of this cancer entity.

The cells that express THBS4 and secrete it to the extracellular space were identified as cancerassociated fibroblasts of the myofibroblast phenotype. Since the expression in normal fibroblast 

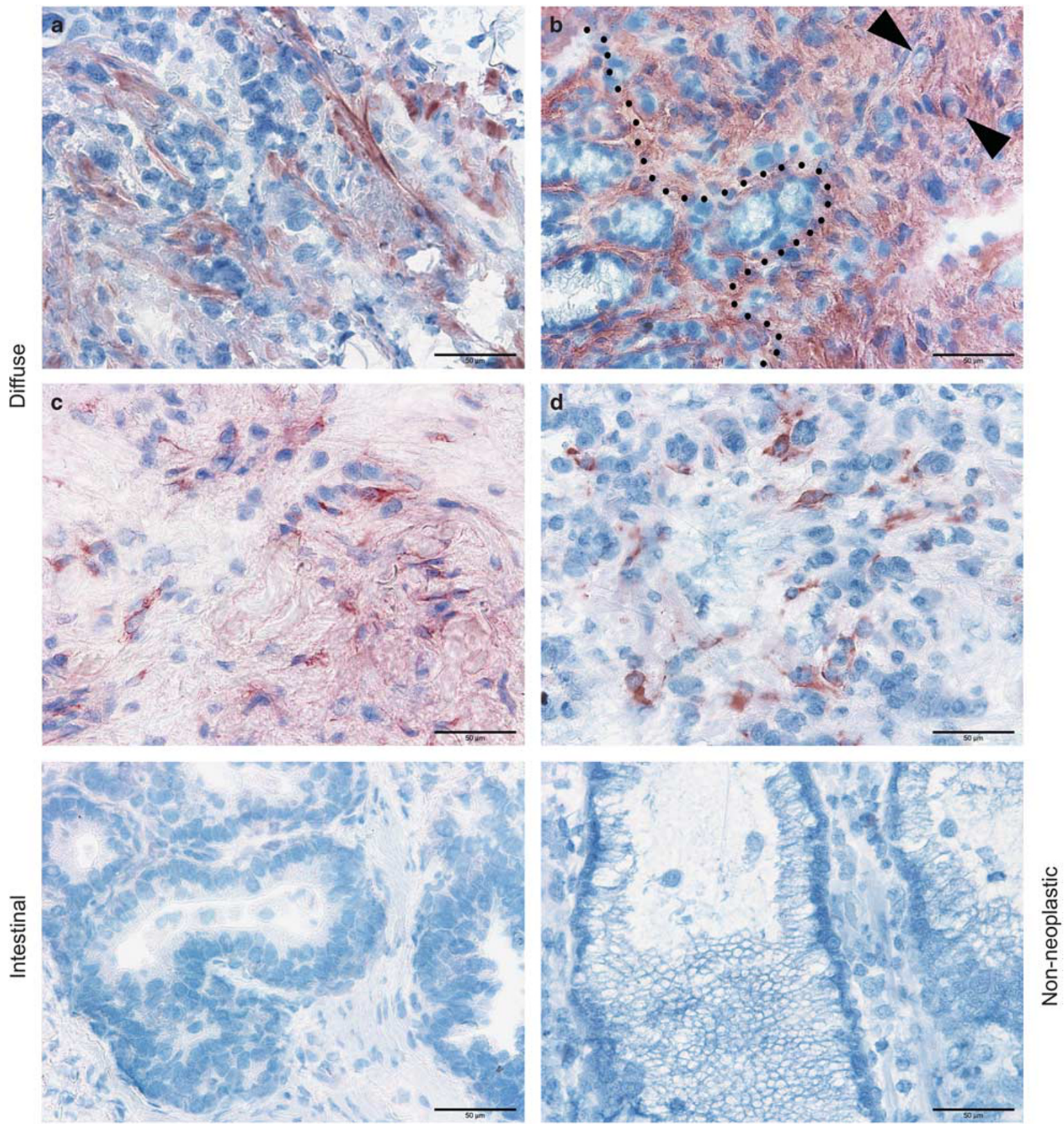

Figure 3 THBS4 expression in human diffuse and intestinal-type gastric adenocarcinomas and non-neoplastic gastric mucosa. Immunohistochemical detection of THBS4 (red) was performed on $10 \mu \mathrm{m}$ thin cryosections. Cell nuclei were counterstained using hematoxylin (blue). In diffuse tumors, THBS4 expression was predominantly observed as fibrillar extracellular matrix structures of the tumor stroma (a-d). Occasionally, cytosolic positivity of cells resembling fibroblasts was detected (c, d). Expression was especially strong in tumor cell nests (a, c) and in regions of invasion into healthy epithelium (dotted line in b). Examples of signet ring cells are indicated with arrowheads. No specific THBS4 expression could be identified within intestinal-type tumors and epithelium and stroma of nonneoplastic gastric mucosa (region depicted was on the same specimen slide as diffuse-type sample a). Representative sections are shown, respectively. Negative controls were obtained by omission of primary antibody (data not shown). Pictures are $\times 400$ magnified with scale bars representing $50 \mu \mathrm{m}$ each.

counterparts was reduced, and no explicit expression could be detected in the normal skin foreheadderived fibroblast line 142BR, THBS4 expression seems to be an attribute of particular, potentially activated, fibroblasts. In the context of diffuse-type gastric malignant transformation, THBS4 expression was proven to be triggered by the tumor cells. However, not all tumor cells have the ability to stimulate it. Tumor cells from diffuse/poorly differentiated gastric adenocarcinomas of the scirrhous 

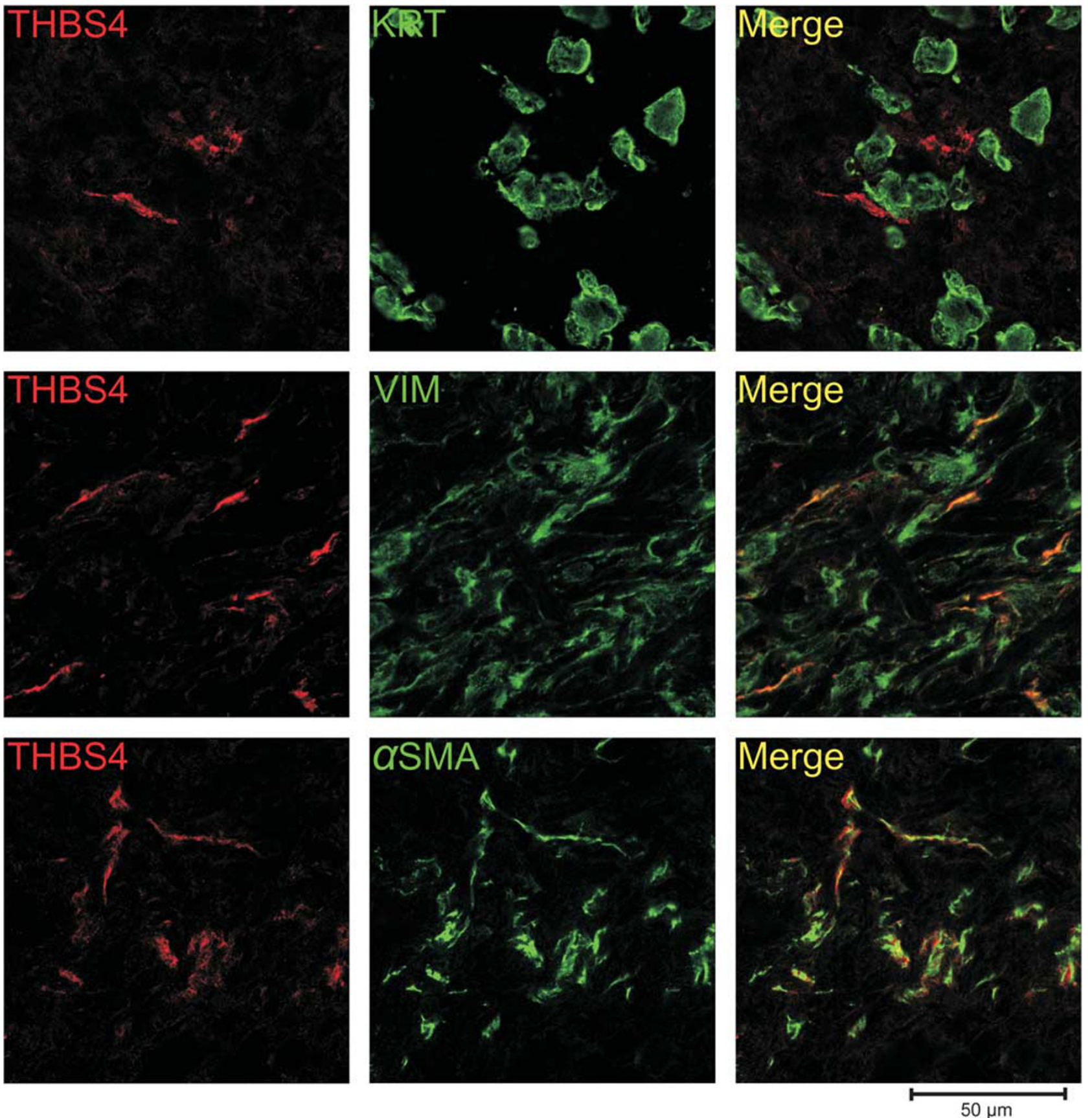

Figure 4 Colocalization of THBS4 and cytokeratin, vimentin and $\alpha$-smooth muscle actin in human diffuse-type gastric adenocarcinomas. Simultaneous fluorescent immunohistochemical detection of THBS4 in red and pan-cytokeratin (KRT), vimentin (VIM) or $\alpha$-smooth muscle actin $(\alpha \mathrm{SMA})$ in green was performed on $10 \mu \mathrm{m}$ thin cryosections. Signals were scanned using a confocal laser scanning microscope. Representative pictures of single confocal sections are shown, respectively. Negative controls were obtained by omission of primary antibodies and scanned with identical settings (pinhole, excitation, frame average, etc.) to positive stainings, respectively (data not shown).

type (OCUM-2M, OCUM-8) stimulated THBS4 expression, whereas tumor cells derived from diffuse/poorly differentiated gastric adenocarcinomas of the medullary type (MKN-45) did not.

Besides differences in the type of gastric tumor that they are derived from, the two OCUM lines differ from MKN-45 in several ways. ${ }^{31,32,34}$ In vitro, OCUM cells exclusively grow in suspension (single or in cell clusters), whereas MKN-45 cells predominantly grow adherent as mono or multi- layers with only few cells being suspended. This behavior is not characteristic for diffuse-type gastric tumors or their cell lines. Additionally, MKN-45 has qualities of not only ordinary gastric mucosa but also intestinal metaplasia, one of the precursor lesions of intestinal-type gastric adenocarcinomas. Therefore, MKN-45 does not seem typical of diffusetype gastric adenocarcinomas, which could account for the missing effect on THBS4 expression as seen in our study. 
At the moment, we cannot exclude that other cell entities (eg leukocytes), reactive oxygen species, hypoxia, mechanical stress and alterations in
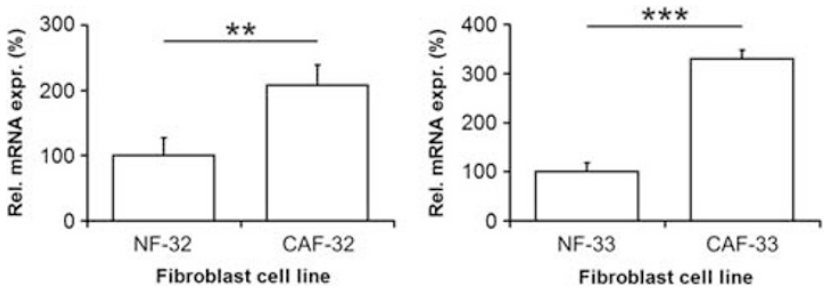

the extracellular matrix might be responsible for enhanced THBS4 expression in fibroblasts of diffuse-type gastric adenocarcinomas as well.

Figure 5 THBS4 mRNA expression in human diffuse-type gastric adenocarcinoma-derived cancer-associated fibroblasts and healthy counterpart-derived normal fibroblasts. Two cell lines of matched diffuse-type gastric adenocarcinoma-derived cancer-associated fibroblasts (CAF-32, CAF-33) and healthy counterpart-derived normal fibroblasts (NF-32, NF-33) were analyzed. The mRNA abundance was examined by means of quantitative real-time PCR. Quantitation was done relative to the transcript of actin, $\beta$ (ACTB) and expression levels in NF-lines were set to $100 \%$, respectively. Significance in differential expression was assessed using $t$-test $\left({ }^{*} P<0.01 ;{ }^{* * *} P<0.001\right)$. Error bars represent integrated standard errors of the mean.

\section{OCUM-2M}
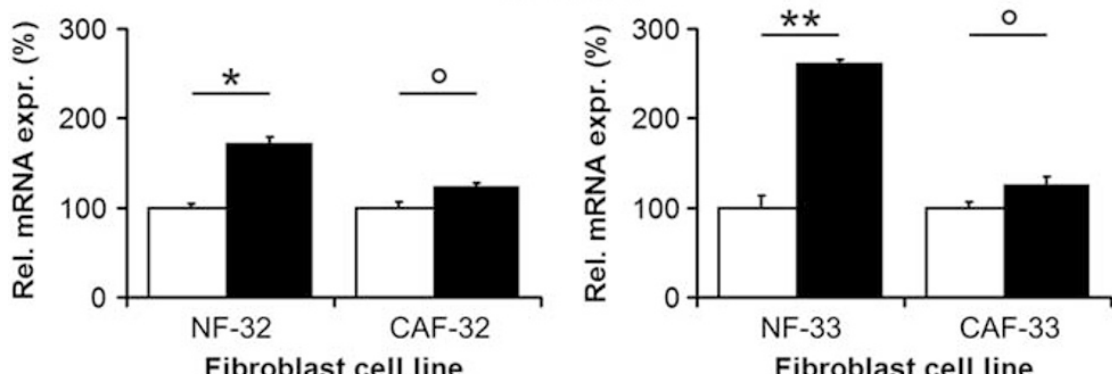

Fibroblast cell line

OCUM-8

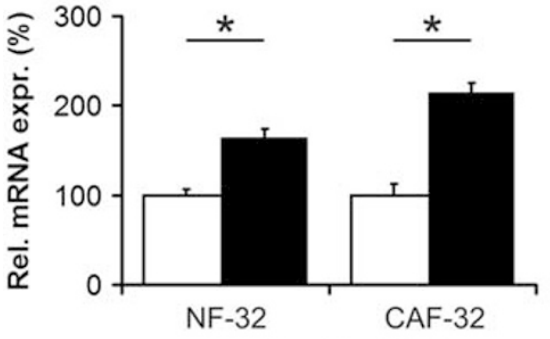

Fibroblast cell line

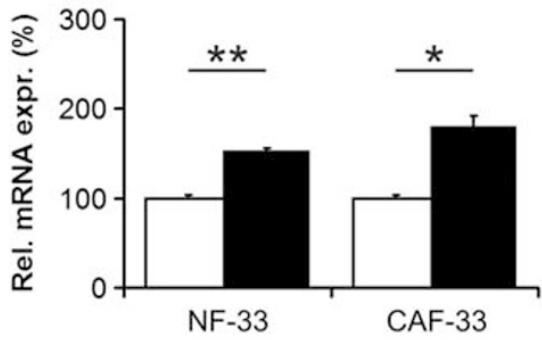

Fibroblast cell line

MKN-45

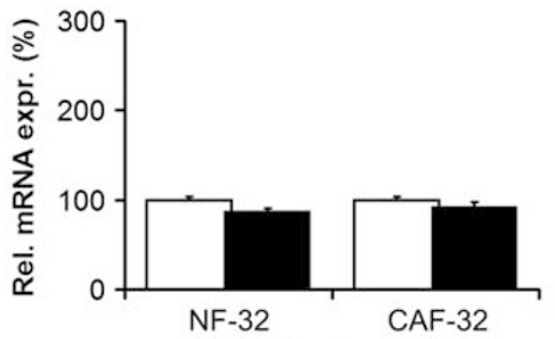

Fibroblast cell line

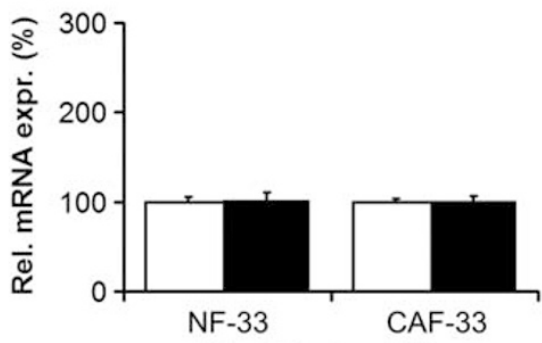

Fibroblast cell line

Control medium

Conditioned medium

Figure 6 Changes in THBS4 mRNA expression in human diffuse-type gastric adenocarcinoma-derived cancer-associated fibroblasts and healthy counterpart-derived normal fibroblasts upon stimulation with tumor cell-conditioned media. Two cell lines of matched diffuse-type gastric adenocarcinoma-derived cancer-associated fibroblasts (CAF-32, CAF-33) and healthy counterpart-derived normal fibroblasts (NF-32, NF-33) were analyzed. Fibroblasts were incubated for $48 \mathrm{~h}$ with conditioned medium derived from human diffuse gastric cancer cell line OCUM-2M, OCUM-8 or MKN-45. Fresh tumor cell-specific medium was used as control medium, respectively. All experiments were run in triplicate with control experiments run on the same plate. THBS4 mRNA abundance was examined by means of quantitative real-time PCR. Quantitation was done relative to the transcript of GAPDH and expression levels in control medium-treated fibroblasts were set to $100 \%$, respectively. Significance in differential expression was assessed using $t$-test $\left({ }^{\circ} P<0.1\right.$; $\left.{ }^{*} P<0.05 ;{ }^{*} P<0.01\right)$. Error bars represent integrated standard errors of the mean. Results of representative experiments are shown. 
Table 3 Differential THBS4 mRNA expression with respect to histological type of human gastric adenocarcinoma in three independent microarray data sets in comparison to this study

\begin{tabular}{|c|c|c|c|c|c|}
\hline Diff. vs int. & Chen & Boussioutas & Hippo & Meta & This study \\
\hline FC $(\log 2)$ & 1.44 & 0.96 & 1.12 & 1.17 & 5.35 \\
\hline$P$-value & $1.95 \mathrm{E}-05^{* * *}$ & $0.0008^{* * *}$ & 0.1949 & $0.0001 * * *$ & $4.66 \mathrm{E}-12^{* * *}$ \\
\hline$Q$-value & 0.0031 & 0.0195 & 0.8083 & 0.0078 & $8.19 \mathrm{E}-08$ \\
\hline
\end{tabular}

Data were obtained from http://human-genome.kribb.re.kr/stomach, ${ }^{36}$ an online service allowing the evaluation of single genes in the data of three major microarray studies on gastric adenocarcinoma ${ }^{10,14,53}$ and their meta-analysis. Statistical significance in differential expression was estimated by $t$-test $\left({ }^{* *} P<0.001\right)$. Calculation of $Q$-values from the corresponding $P$-values was performed to control for the false discovery rate that occurs in multiple hypothesis testing. ${ }^{54}$ Metaanalysis of the data sets was performed as follows: The meta fold changes (FC) were calculated by taking an arithmetic mean of the individual values and meta $P$ and $Q$-values were calculated by taking the arithmetic mean of $\log (P$-values $)$ and $\log (Q$-values $)$ of the individual data sets. The $Q$-value for THBS4 in this study was calculated using QVALUE software $^{54,55}$ from the non-corrected $P$-value ( $P$-values of all genes inputted).

Cell lines of not only normal fibroblasts but also cancer-associated ones, which already possess higher endogenous expression levels, were able to increase THBS4 expression upon stimulation by tumor cells, which indicates that their endogenous expression levels had not yet reached saturation. This would imply that the extent of stimulation and activation regulates expression in a dose- and timedependent manner, rather than in an on-off switch mode. The kinetics of THBS4 expression in fibroblasts might be elucidated by repeated stimulation at different time points. Another important question to address in the future is to determine which factor/ $s$ released by the tumor cells drive THBS4 expression in fibroblasts. There is some evidence to suggest that growth factors, such as transforming growth factor $\beta$ (TGF- $\beta$ ), platelet-derived growth factor (PDGF) or fibroblast growth factor 2 (FGF2), are the promoters of this effect. All are key regulators of fibroblast activation and are overexpressed in a range of tumor entities. ${ }^{39}$ In line with that assumption, the transcripts of most of these factors and/or their receptors were found to be consistently overexpressed in the diffuse tumors of this study (data not shown). Of all the factors, TGF- $\beta$ might be the most likely trigger for THBS4 expression, since it is known to be connected to an enhancement of collagen production by fibroblasts in certain diffuse-type gastric tumors. ${ }^{40}$

The function of THBS4 within the reactive stroma of diffuse-type gastric cancer remains elusive. Studies of non-tumor tissues have provided little information about the physiological functions of THBS4. For example, in the developing nervous system, THBS4 was found to represent an attractive substrate for certain neurites and to promote neurite outgrowth in a variety of neuron types. ${ }^{41}$ Furthermore, THBS4 has been shown to stimulate the proliferation of erythroid cells, hematopoietic precursors (CD34-positive cells), skin fibroblasts and kidney epithelial cells. ${ }^{42,43}$ However, the protein also has anti-proliferatory effects, for example in endothelial cells. ${ }^{42}$ Other proposed functions include a supportive role in myoblast adhesion ${ }^{44}$ and interactions with other extracellular matrix proteins, such as certain collagens, laminin $\alpha 1$, fibronectin and matrilin $2 .{ }^{45}$ Given this information, hypothetical functions of THBS4 in the scenario of diffuse-type gastric cancer could include stimulation of proliferation of tumor cells or of other cell types and a facilitation of migratory behavior of tumor cells that elevates the invasive potential of the tumor.

Since multiple additional cancer entities (eg lobular carcinomas of the breast, mesoblastic nephroma, Wilms tumors, grade I pilocytic astrocytomas $^{46-49}$ ) display overexpression of THBS4, at least on the transcriptional level, THBS4 might be of more global relevance for malignancy, rather than being restricted to diffuse-type adenocarcinomas of the stomach, solely.

The famous pro-oncogenic ${ }^{50,51}$ molecule CD44 had previously been identified as a cellular receptor of the C-terminal peptide of THBS $4,{ }^{52}$ which underlines another potential link between THBS4 and malignancy.

The present study provides the first transcriptome-wide, comparative analysis of the expression profiles of human diffuse and intestinal-type gastric adenocarcinomas. It is the first to describe THBS4 as a potent marker for diffuse-type gastric adenocarcinomas (on mRNA and protein level) and initially characterizes it as a heavily accumulated constituent of the stromal aspect of this disease entity.

Explanations of frequently used statistical and bioinformatic terms can be obtained from Supplementary Table S5.

\section{Acknowledgements}

We thank Dr Wolfgang Haensch (MD, Research Group Surgical Oncology, Experimental and Clinical Research Center, Berlin, Germany), Dr Ellen Fietze (MD, Practice for Pathology, Bundeswehrkrankenhaus, Berlin, Germany) and PD Dr Michael Vieth (MD, Pathology of Klinikum Bayreuth, Bayreuth, Germany) for pathological evaluations, fruitful discussions and reading of the manuscript.

\section{Disclosure/conflict of interest}

The authors declare no conflict of interest.

\section{References}

1 Siewert JR, Bottcher K, Stein HJ, et al. Relevant prognostic factors in gastric cancer: ten-year results of the German Gastric Cancer Study. Ann Surg 1998;228:449-461. 
2 Hundahl SA, Phillips JL, Menck HR. The National Cancer Data Base Report on poor survival of U.S. gastric carcinoma patients treated with gastrectomy: Fifth Edition American Joint Committee on Cancer staging, proximal disease, and the 'different disease' hypothesis. Cancer 2000;88:921-932.

3 Dicken BJ, Bigam DL, Cass C, et al. Gastric adenocarcinoma: review and considerations for future directions. Ann Surg 2005;241:27-39.

4 Bang YJ, Van Cutsem E, Feyereislova A, et al. Trastuzumab in combination with chemotherapy versus chemotherapy alone for treatment of HER2positive advanced gastric or gastro-oesophageal junction cancer (ToGA): a phase 3, open-label, randomised controlled trial. Lancet 2010;376:687-697.

5 Lauren P. The two histological main types of gastric carcinoma: diffuse and so-called intestinal-type carcinoma. An attempt at a histo-clinical classification. Acta Pathol Microbiol Scand 1965;64:31-49.

6 Day DW, Jass JR, Price AB, et al. Epithelial tumours of the stomach. In: Day DW, Morson BC (eds). Morson and Dawson's Gastrointestinal Pathology, 4th edn. Blackwell Science: Malden, Massachusetts, USA, 2003, pp 162-195.

7 Werner M, Becker KF, Keller G, et al. Gastric adenocarcinoma: pathomorphology and molecular pathology. J Cancer Res Clin Oncol 2001;127:207-216.

8 Vauhkonen M, Vauhkonen H, Sipponen P. Pathology and molecular biology of gastric cancer. Best Pract Res Clin Gastroenterol 2006;20:651-674.

9 Roukos D, Agnantis N, Fatouros M, et al. Gastric cancer: introduction, pathology, epidemiology. Gastric Breast Cancer 2002;1:1-3.

10 Boussioutas A, Li H, Liu J, et al. Distinctive patterns of gene expression in premalignant gastric mucosa and gastric cancer. Cancer Res 2003;63:2569-2577.

11 Jinawath N, Furukawa Y, Hasegawa S, et al. Comparison of gene-expression profiles between diffuse- and intestinal-type gastric cancers using a genome-wide cDNA microarray. Oncogene 2004;23:6830-6844.

12 Kim B, Bang S, Lee S, et al. Expression profiling and subtype-specific expression of stomach cancer. Cancer Res 2003;63:8248-8255.

$13 \mathrm{Wu} \mathrm{CM}$, Lee YS, Wang $\mathrm{TH}$, et al. Identification of differential gene expression between intestinal and diffuse gastric cancer using cDNA microarray. Oncol Rep 2006;15:57-64.

14 Hippo Y, Taniguchi H, Tsutsumi S, et al. Global gene expression analysis of gastric cancer by oligonucleotide microarrays. Cancer Res 2002;62:233-240.

15 Ribeiro MM, Sarmento JA, Sobrinho Simoes MA, et al. Prognostic significance of Lauren and Ming classifications and other pathologic parameters in gastric carcinoma. Cancer 1981;47:780-784.

16 Stemmermann GN, Brown C. A survival study of intestinal and diffuse types of gastric carcinoma. Cancer 1974;33:1190-1195.

17 Henson DE, Dittus C, Younes M, et al. Differential trends in the intestinal and diffuse types of gastric carcinoma in the United States, 1973-2000: increase in the signet ring cell type. Arch Pathol Lab Med 2004;128:765-770.

18 Lauren PA, Nevalainen TJ. Epidemiology of intestinal and diffuse types of gastric carcinoma. A time-trend study in Finland with comparison between studies from high- and low-risk areas. Cancer 1993;71: 2926-2933.
19 Arias AM. Epithelial mesenchymal interactions in cancer and development. Cell 2001;105:425-431.

20 Matrisian LM, Cunha GR, Mohla S. Epithelial-stromal interactions and tumor progression: meeting summary and future directions. Cancer Res 2001;61:3844-3846.

21 Fenoglio-Preiser C, Carneiro F, Correa $\mathrm{P}$, et al. Tumours of the stomach. In: Hamilton SR, Aaltonen LA (eds). Pathology and Genetics of Tumours of the Digestive System. 3 edn., Vol. 2, IARC Press: Lyon, 2000, pp 37-67.

22 Watanabe H, Jass JR, Sobin LH. Histological classification of gastric tumours. In: Watanabe H, Jass JR, Sobin LH (eds). Histological Typing of Oesophageal and Gastric Tumours, 2 edn. Springer-Verlag: Berlin, 1990, pp 7-10.

23 Sobin LH, Wittekind C. Stomach. In: Sobin LH, Wittekind C (eds). TNM Classification of Malignant Tumors. Union Internationale Contre le Cancer, 5 edn. Wiley-Liss: New York, 1997.

$24 \mathrm{Wu}$ Z, Irizarry RA, Gentleman R, et al. A model based background adjustment for oligonucleotide expression arrays. Johns Hopkins University, Department of Biostatistics Working Papers. 2004; Working Paper 1.

25 Benjamini Y, Hochberg Y. Controlling the false discovery rate: a practical and powerful approach to multiple testing. J Roy Statist Soc Ser B 1995;57:289-300.

26 Bonferroni CE. Il calcolo delle assicurazioni su gruppi di teste. In: SO Carboni (ed). Studi in Onore del Professore Salvatore Ortu Carboni. Tipografia del Senato: Rome, 1935, pp 13-60.

27 Bluthgen N, Brand K, Cajavec B, et al. Biological profiling of gene groups utilizing Gene Ontology. Genome Inform 2005;16:106-115.

28 Rubie C, Kempf K, Hans J, et al. Housekeeping gene variability in normal and cancerous colorectal, pancreatic, esophageal, gastric and hepatic tissues. Mol Cell Probes 2005;19:101-109.

29 Schmittgen TD, Livak KJ. Analyzing real-time PCR data by the comparative C(T) method. Nat Protoc 2008;3:1101-1108.

30 Juttner S, Wissmann C, Jons $\mathrm{T}$, et al. Vascular endothelial growth factor-D and its receptor VEGFR3: two novel independent prognostic markers in gastric adenocarcinoma. J Clin Oncol 2006;24:228-240.

31 Yashiro M, Chung YS, Nishimura S, et al. Establishment of two new scirrhous gastric cancer cell lines: analysis of factors associated with disseminated metastasis. Br J Cancer 1995;72:1200-1210.

32 Takemura S, Yashiro M, Sunami T, et al. Novel models for human scirrhous gastric carcinoma in vivo. Cancer Sci 2004;95:893-900.

33 Yashiro M, Chung YS, Nishimura S, et al. Fibrosis in the peritoneum induced by scirrhous gastric cancer cells may act as 'soil' for peritoneal dissemination. Cancer 1996;77:1668-1675.

34 Motoyama T, Hojo H, Watanabe H. Comparison of seven cell lines derived from human gastric carcinomas. Acta Pathol Jpn 1986;36:65-83.

35 Gabbiani G, Ryan GB, Majne G. Presence of modified fibroblasts in granulation tissue and their possible role in wound contraction. Experientia 1971;27:549-550.

$36 \mathrm{Kim}$ SY, Kim JH, Lee HS, et al. Meta- and gene set analysis of stomach cancer gene expression data. Mol Cells 2007;24:200-209.

37 Lawler J, McHenry K, Duquette M, et al. Characterization of human thrombospondin-4. J Biol Chem 1995;270:2809-2814. 
38 Norsett KG, Laegreid A, Midelfart $\mathrm{H}$, et al. Gene expression based classification of gastric carcinoma. Cancer Lett 2004;210:227-237.

39 Kalluri R, Zeisberg M. Fibroblasts in cancer. Nat Rev Cancer 2006;6:392-401.

40 Mahara K, Kato J, Terui T, et al. Transforming growth factor beta 1 secreted from scirrhous gastric cancer cells is associated with excess collagen deposition in the tissue. Br J Cancer 1994;69:777-783.

41 Arber S, Caroni P. Thrombospondin-4, an extracellular matrix protein expressed in the developing and adult nervous system promotes neurite outgrowth. J Cell Biol 1995;131:1083-1094.

42 Congote LF, Difalco MR, Gibbs BF. The C-terminal peptide of thrombospondin-4 stimulates erythroid cell proliferation. Biochem Biophys Res Commun 2004;324:673-678.

43 Sadvakassova G, Dobocan MC, Difalco MR, et al. Regulator of differentiation 1 (ROD1) binds to the amphipathic C-terminal peptide of thrombospondin-4 and is involved in its mitogenic activity. J Cell Physiol 2009;220:672-679.

44 Adams JC, Lawler J. Cell-type specific adhesive interactions of skeletal myoblasts with thrombospondin-1. Mol Biol Cell 1994;5:423-437.

45 Narouz-Ott L, Maurer P, Nitsche DP, et al. Thrombospondin-4 binds specifically to both collagenous and non-collagenous extracellular matrix proteins via its Cterminal domains. J Biol Chem 2000;275:37110-37117.

46 Korkola JE, DeVries S, Fridlyand J, et al. Differentiation of lobular versus ductal breast carcinomas by expression microarray analysis. Cancer Res 2003;63: 7167-7175.
47 Rorive S, Maris C, Debeir O, et al. Exploring the distinctive biological characteristics of pilocytic and low-grade diffuse astrocytomas using microarray gene expression profiles. J Neuropathol Exp Neurol 2006;65:794-807.

48 Sugimura J, Yang XJ, Tretiakova MS, et al. Gene expression profiling of mesoblastic nephroma and Wilms tumors-comparison and clinical implications. Urology 2004;64:362-368.

49 Turashvili G, Bouchal J, Burkadze G, et al. Differentiation of tumours of ductal and lobular origin: II. Genomics of invasive ductal and lobular breast carcinomas. Biomed Pap Med Fac Univ Palacky Olomouc Czech Repub 2005;149:63-68.

50 Goodison S, Urquidi V, Tarin D. CD44 cell adhesion molecules. Mol Pathol 1999;52:189-196.

51 Naor D, Sionov RV, Ish-Shalom D. CD44: structure, function, and association with the malignant process. Adv Cancer Res 1997;71:241-319.

52 Sadvakassova G, Dobocan MC, Congote LF. Osteopontin and the C-terminal peptide of thrombospondin-4 compete for CD44 binding and have opposite effects on CD133+ cell colony formation. BMC Res Notes 2009;2:215.

53 Chen X, Leung SY, Yuen ST, et al. Variation in gene expression patterns in human gastric cancers. Mol Biol Cell 2003;14:3208-3215.

54 Storey JD, Tibshirani R. Statistical significance for genomewide studies. Proc Natl Acad Sci USA 2003;100:9440-9445.

55 Storey JD. A direct approach to false discovery rates. Journal of the Royal Statistical Society Series B 2002;64:479-498.

Supplementary Information accompanies the paper on Modern Pathology website (http://www.nature.com/ modpathol) 